có sự liên quan giữa nồng độ các cytokine trước và sau điều trị với kết quả điều trị.

Hiện nay các nghiên cứu ở trong và ngoài nước về mối liên quan giữa nồng độ các cytokine (IL-2, IL-6, IL-8, IL-10, IL-12, IL-17, TNF- $\alpha$, IFN- $Y$ ) trước và sau điêu trị với kết quả điều trị chưa được công bố. Do vậy, trong nghiên cứu này chúng tôi còn hạn chế đó là: chưa có tài liệu tham khảo để so sánh về nội dung này.

\section{KẾT LUẬN}

Nghiên cứu 35 bệnh nhân vảy nến thông thường mức độ nặng, điều trị bằng uống Cyclosporin A với liểu 2,5-3mg/kg/ngàysau 10 tuần, chúng tôi rút ra một số kết luận:

Nồng độ IL-6, IL-10, IL-12, IL-17, TNF-c sau điêu trị đều giảm hơn so với trước điêu trị, tuy nhiên sự thay đổi chưa có ý nghĩa thông kê với $p>0,05$. Nồng độ IL-2, IL-8 không có sự thay đổi so với trước điều trị với $p>0,05$. Riêng nồng độ IFN- y sau điêu trị giảm so với trước điều trị có ý nghĩa thống kê với $p<0,05$.

Chưa thấy mối liên quan giữa nồng độ một số cytokine trước và sau điêu trị với kết quả điều trị trên lâm sàng theo PASI.

\section{TÀI LIÊU THAM KHẢO}

1. Đặng Văn Em. (2013). Bệnh vảy nến: Sinh bệnh hộc và chiến lược điều trị. Sách chuyên khảo Nhà xuất bản y học., 236 tr.
2. WHO. (2016). The burden of psoriasis. Global report on psoriasis., Chapter 2.

3. Hawkes. J. E., Chan. T. C., Krueqer. J. G. (2017). Psoriasis pathoqenesis and the development of novel targeted immune therapies. Journal of Allergy and Clinical Immunoloqv., 140(3): 645-653.

4. Coimbra. S., Fiqueiredo. A., Castro. E., et al. (2012). The roles of cells and cytokines in the pathogenesis of psoriasis. International journal of dermatology., 51(4): 389-398.

5. Pham Diếm Thuý., Đăng Văn Em., Lý Tuấn Khải. (2019). Nghiên cứu sự thay đổi nồng độ môt số cytokine trước và cytokine trước và sau điều trị bệnh vảy nến thông thường bằng chiếu UVB-311nm kết hợp uống Methotrexate liều thấp. Tap chí y dược lâm sàng 108., 3.

6. Phan Huy Thuuc. (2015). Nghiên cứu đặc điểm lâm sàng và mối liên quan giữa nồng độ cytokine với kết quả điều trị bệnh vảy nến thông thường bằng methotrexate. Luận án tiến sỹ y học, Đại học Y hà nôi., 129 tr.

7. Haider. A. S., Lowes. M. A., Suárez-Fariñas. M., et al. (2008). Identification of cellular pathways of" type 1," Th17 T cells, and TNF-and inducible nitric oxide svnthase-producina dendritic cells in autoimmune inflammation through pharmacogenomic study of cyclosporine $A$ in psoriasis. Journal of immunoloqv., 180(3): 1913.

8. Ikonomidis. I., Papadavid. E., Makavos. G., et al. (2017). Lowering interleukin-12 activity improves myocardial and vascular function compared with tumor necrosis factor-a antagonism or cyclosporine in psoriasis. Circulation: Cardiovascular Imaging., 10(9): 006283.

\title{
KHẢO SÁT MộT SỐ ĐĂC ĐIỂM VỀ HÌNH THÁI TỔN THƯƠ'NG TRONG HộI CHỬNG ĐộNG MẠCH CHỦ NGỰC CẤP
}

\section{TÓM TẮT}

Mục tiêu: khảo sát tỷ lệ và mô tả một số đặc điểm về hình thái tổn thương trong hội chứng ĐMic ngực cấp ở nhóm bệnh nhân được nghiên cứu. Đối tượng và phương pháp nghiên cứu: Mô tả tiến cứu, hàng loạt các trường hợp. Bn được chẩn đoán một trong các thể của HC ĐMC ngực cấp và được điều trị tại khoa phẫu thuật tim, bệnh viện Chợ Râyy và khoa phẫu thuật tim mạch, bệnh viện Đaạ Học Y Dược trong thời gian từ tháng 9/2015 đến tháng 9/2018. Kết quả: Trong thời gian 3 năm (9/2015-9/2018), chúng tôi thu thập được 102 trường hợp được chẩn

\footnotetext{
${ }^{1}$ Bệnh viện Quân y 175

${ }^{2}$ Bềnh viện Đại hơ Y Dướ TPHCM

Chịu trách nhiệm chính: Nông Hữu Thọ

Email: huuthomd@gmail.com

Ngày nhận bài: 10/1/2021

Ngày phản biên khoa hoc: 9/2/2021

Ngày duyệt bài: 3/3/2021
}

\section{Nông Hữu Thộ ${ }^{1}$ Phạm Thọ Tuấn Anh ${ }^{2}$, Nguyễn Hoàng Định ${ }^{2}$}

đoán hội chứng ĐMC cấp. Sau khi được hội chẩn tim mạch, có 101 ca được điều trị phẫu thuật. Nhóm tuổi chiếm tỷ lệ cao nhất là độ tuổi $61-70$ tuổi (45,8\%). Các dạng hình thái tổn thương: Nhóm bóc tách kinh điển (AD) chiếm tỷ lệ cao nhất $66,3 \%$, nhóm phình dọa võ (AAR) là 23,8\%, nhóm loét thủng (PAU) là $8,9 \%$, nhóm huyết khối tu thành (IMH) là 23,8\%. Trong $\mathrm{HC}$ ĐMC cấp, vị trí tổn thương chủ yếulà ĐMC ngực đoan lên $(74,3 \%)$. Các vị trí khác có tỷ lệ tổn thương ít gặp hơn, tổn thương đoạn quai $(54,5 \%)$, tổn thương đoạn gốc ĐMC $(29,7 \%)$. Kết luận: Hình thái tổn thương trong hội chứng ĐMC ngực cấp khá đa dang và phức tap, thường gặp vẫn là dạng hình thái bóc tách ĐMC kinh điển $(A D)$ chiếm tỷ lệ cao nhất $66,3 \%$; các hình thái ít găp hơn là loét thủng PAU $8,9 \%$ và huyết khối tụ thành IMH 23,8\%. Tổn thương có thể gặp ở nhiều vị trí khác nhau và chồng lấn lên nhau, thường gặp nhất là ĐMC đoạn lên là 74,3\%. đoạn quai $54,4 \%$.

Từ khóa: Hội chứng động mạch chủ cấp, bóc tách, Huyết khối tụ thành, phình ĐMC. 


\section{SUMMARY \\ SURVEY OF THE MORPHOLOGICAL CHARACTERISTICSIN THE ACUTE AORTIC SYNDROME}

Objectives: The aim of this study was to investigate the proportion and the morphological characteristics of the acute aortic syndrome. Materials and methods: A descriptive study was conducted in a series of 102 patients, suffering the acute aortic syndrome, in Cho Ray hospital and University Medical Centerfrom September 2015 to September 2018. Results: Acute aortic syndrome describes the presentation of patients with one of a number of life-threatening aortic pathologies and morphology that give rise to aortic symptoms. The spectrum of these aortic emergencies include: aortic dissection, aortic intramural hematoma, penetrating atherosclerotic ulcer, aortic aneurysmal rupture.There are 102 patients suffering AAS but 101 patients were performed surgerywith a mean age of $46.3 \pm 21,78$ males $(78.7 \%)$ and 23 females $(23.2 \%)$. The morphological characteristics: A.D: $66,3 \%$; PAU: 8,9\%; IMH 23,8\%; Iatrogenic: $2 \%$ (2/101). Conclusion: Recognition of variations of AAS types: A.D 66,3\%; PAU: 8,9\%; IMH 23,8 \%; Iatrogenic 2\%; ARR $20 \%$. The assessment of the thoracic aorta morphological characteristics are very important. According to the result, the surgeons and interventionists have the feasible strategy forAAS treatment.

Keywords: Acute aortic syndrome (AAS), Multidetector computed tomography (MDCT), aortic dissection (A.D), aortic intramural hematoma (I.M.H), penetrating atherosclerotic ulcer (P.A.U), aortic aneurysmal rupture (A.A.R).

\section{I. ĐĂT VẤN ĐỀ}

Hội chứng ĐMC cấp là một khái niệm khá cập nhật trong giai đoạn hiện nay và được xếp vào nhóm bệnh cảnh cấp cứu của ĐMC ngực, bao gồm một số thể thường gặp như: bóc tách kinh điển (A.D), máu tụ trong thành (IMH), loét thủng xuyên thành (PAU) và phình $Đ M C$ ngực dọa vỡ[1],[8]. Trong những năm gần đây, sự phát triển của các phương pháp $\mathrm{C} Đ H A$, đặc biệt là chụp CLVT đã góp phần mô tả chi tiết các dạng hình thái tổn thương ĐMC. Việc khảo sát hình thái tổn thương động mạch chủ ngực có ý nghĩa quan trọng trong thực hành lâm sàng. Đây là cơ sở cho việc đánh giá chính xác tính chất tổn thương, mức độ lan rộng của tổn thương để đưa ra chiến lược xử trí phù hợp cũng như tiên lượng kết quả điều trị phẫu thuật. Hiện nay, số lượng công trình nghiên cứu chỉ chuyển về hình thái tổn thương trong $\mathrm{HC}$ ĐMC ngực cấp còn khá khiêm tốn. [2][3]. Do vậy, chúng tôi tiến hành nghiên cứu đề tài này nhằm khảo sát tỷ lệ và mô tả các đắc điểm về hình thái tổn thương trong hình thái động mạch chủ ngực cấp tính. Từ đó, góp phần vào công tác chân đoán sớm và xử trí ḳ̣p thời các trường hợp bệnh nhân có HC ĐMC cấp.

\section{II. ĐỐI TƯỢNG VÀ PHƯƠNG PHÁP NGHIÊN CỨU}

2.1. Đối tượng nghiên cứu. Các bệnh nhân được chẩn đoán một trong các thể của hội chứng động mạch chủ ngực cấp tính, được nhập viện và điều trị phẫu thuật tại khoa phẫu thuật tim bệnh viện Chợ Rẫy và khoa Phẫu thuật tim mạch, Bệnh viện Đaai Học Y Dược trong thời gian từ tháng 9/2015 đến $9 / 2018$ thỏa mãn các tiêu chí chọn mẫu.

2.2. Phương pháp nghiên cứu. Thiết kế nghiên cứu mô tả dọc tiến cứu.

2.3. Xử lý số liệu. Các thông tin về hành chính và các số liệu nghiên cứu được nhập vào máy tính theo mã số bệnh nhân đã được mã hóa, và được xử lý bằng phần mềm thống kê $y$ học SPSS 26.

\section{KẾT QUẢ NGHIÊN CỨU}

3.1. Đặc điểm chung của nhóm bệnh nhân nghiên cứu

- Đặc điểm về giới

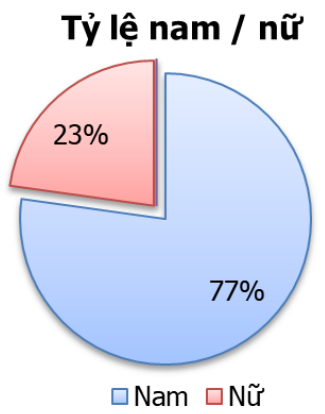

Biểu đồ 3.1.Phân bố bệnh nhân theo giới

Nhận xét: Số lượng bệnh nhân nam cao hơn nữ gấp 3,4 lần với tỷ lệ nam $77,2 \%$ (78/101) và tỷ lệ nữ 22,8 \% (23/101).

\section{- Đăcc điểm tuổi và nhóm tuổi}

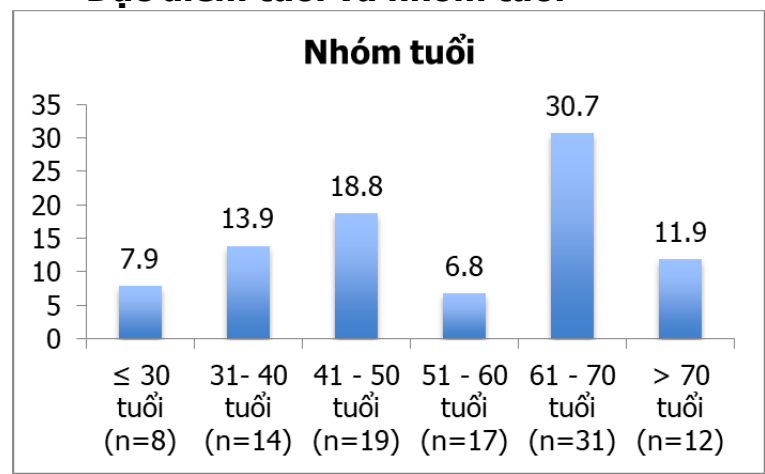

Biểu đồ 3.2. Biểu đồ phân bố nhóm tuổi

Nhận xét: Tuổi trung bình của nhóm BN nghiên cứu là $54,1 \pm 14,9$. 
Trong đó có bênh nhân trẻ tuổi nhất là 20 tuổi, bệnh nhân lớn tuổi nhất là 79 tuổi.

Nhóm tuổi từ 61-70 tuổi có tỷ lế cao nhất là 29,7\%; nhóm tuổi từ 41-50 và nhóm tuổi từ 5160 cũng chiếm tỷ lệ khá cao lần lượt là $18,8 \%$ và $17,8 \%$. Nhóm tuổi hiếm găp nhất là nhóm <20 tuổi chỉ có 1 trường hợp.

3.2. Triệu chứng khởi phát của hội chứng động mach chủ cấp

Bảng 3.1. Triệu chứng khởi phát lúc nhập viện

\begin{tabular}{|c|c|c|}
\hline Lý do nhập viện & Số BN & Tỷ lệ \% \\
\hline Tình cờ phát hiện & 3 & 3.0 \\
\hline Đau ngực & $\mathbf{5 1}$ & $\mathbf{5 0 , 5}$ \\
\hline Mệt khó thở & 31 & 30.7 \\
\hline Ngất & $\mathbf{5}$ & $\mathbf{5 . 0}$ \\
\hline NMCT & 6 & 5.9 \\
\hline Sau can thiệp/thủ thuật & $\mathbf{2}$ & $\mathbf{2 . 0}$ \\
\hline Nhập viện vì lý do khác & 3 & 3.0 \\
\hline
\end{tabular}

Nhận xét: Triêu chứng thường găp nhất là đau ngực chiếm 50,5\%. Khó thở chiếm 30,7\%.

3.3. Đặc điểm siêu âm tim qua thành ngực theo từng loại tổn thương

Bảng 3.2. Đặc điểm siêu âm tim qua thành ngực theo loại tổn thương

\begin{tabular}{|c|c|c|c|c|}
\hline $\begin{array}{c}\text { Đặc điếm siếu âm tim } \\
\text { qua thành ngực }\end{array}$ & $\begin{array}{c}\text { Bóc tách kinh } \\
\text { điển } \mathbf{( n = 4 6 )}\end{array}$ & $\begin{array}{c}\text { Loét thủng } \\
(\mathbf{n = 9})\end{array}$ & $\begin{array}{c}\text { Huyết khối } \\
\text { thành(n=24) }\end{array}$ & $\begin{array}{c}\text { Phình doa võ̃ } \\
(\mathbf{n = 2 0})\end{array}$ \\
\hline $\mathrm{EF}<30 \%$ & $1(2,2 \%)$ & 0 & 0 & 0 \\
\hline $\mathrm{EF} 30 \%-40 \%$ & $2(4,4 \%)$ & 0 & 0 & 0 \\
\hline $\mathrm{EF} 40 \%-50 \%$ & $1(2,2 \%)$ & $1(11,1 \%)$ & $1(4,2 \%)$ & $3(15 \%)$ \\
\hline $\mathrm{EF}>50 \%$ & $42(91,2 \%)$ & $8(88,9 \%)$ & $23(95,8 \%)$ & $17(85 \%)$ \\
\hline Hở van ĐMC mức độ vữa & 19 & 0 & 3 & 4 \\
\hline Van ĐMC hai mảnh & 3 & 0 & 0 & 9 \\
\hline Sưi, vối hóa van ĐMC & 6 & 4 & 7 & 12 \\
\hline Lô rách trên siêu âm & 32 & 5 & 10 & 9 \\
\hline
\end{tabular}

Nhấn xét: Hầu hết phân suất tống máu trong các loại tốn thương đều > 50\%. Ớ nhóm bóc tách, ghi nhận mức độ hở van ĐMC vừà chiếm 19/46 TH và ghi nhận có lỗ rách trên siêu âm tim là 32/46.

\section{4. Đặc điểm chụp CLĐT theo loại tổn thương}

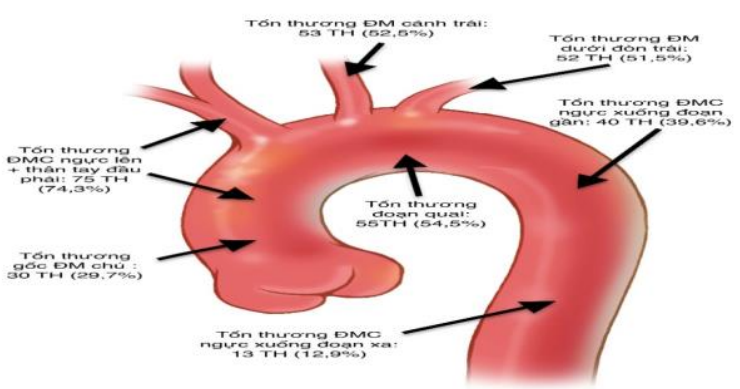

Hình 3.1. Vị trí tổn thương ĐMC ngực trên CLDT trong $H C \oplus M C$

Nhận xét: Trong hội chứng ĐMC cấp, vị trí tổn thương chủ yếu là ĐMC ngực đoạn lên và đoạn quai lần lượt là $74,3 \%$ và $54,5 \%$. Ghi nhận có $29,7 \%$ TH tổn thương gốc ĐMC.

3.5. Các dạng hình thái tổn thương trong hội chứng ĐMC cấp

Nhân xét: Dựa trên bảng phân loại của Svensson và khuyến cáo của ESC 2014, chúng tôi ghi nhận có nhiều hình thái tổn thương đa dang trong hội chứng $Đ M C$ cấp, thường gặp nhất vẩn là hình thái bóc tách $Đ M C$ kinh điển $A D$ chiếm tỷ lệ cao nhất 66,3\%; các hình thái ít gặp hơn là loét thủng PAU và huyết khối tụ thành IMH với tỷ lệ lần lượt là $8,9 \%$ và $23,8 \%$; nhóm có tỷ lệ ít gặp nhất là tổn thương ĐMC cấp tính sau thủ thuật (iatrogenic) có tỷ lệ 2\% (2/101).

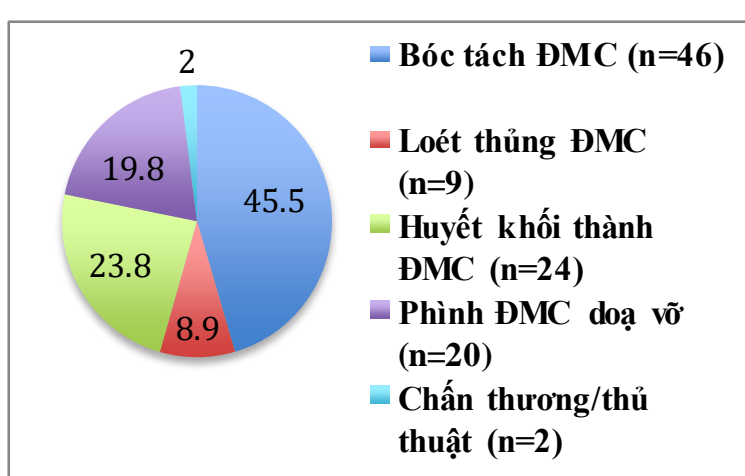

Biểu đồ 3.3. Các dạng tổn thương trong hội chứng ĐMC cấp

\section{BÀN LUÂN}

Theo các báo cáo tổng hợp, tần xuất của hội chứng ĐMC ngực cấp trong dân số tại Mỹ là 2,6$3,5 \mathrm{ca} / 100000$ dân/ năm, chủ yếu tập trung ở nam giới chiếm $2 / 3$ và tuổi trung bình là 63 tuổi.[3] Tuy nhiên, ở hội chứng ĐMC ngực cấp, bệnh có thể kết hợp với yếu tố nguy cơ như mõ máu, huyết áp, tiểu đường, bệnh mạch máu ngoại vi [5]... nên sẽ có trường hợp hội chứng ĐMC ngực xuất hiện ở các bệnh nhân trẻ tuổi, ghi nhân được bn trẻ nhất là 20 tuổi, lớn tuổi nhất 79 tuổi trong nhóm bệnh nhân được nghiên cứu.

Báo cáo của hội tim mạch Châu Âu về chẩn đoán và điều trị bềnh lý ĐMC chủ cho thấy theo Phân tích của hội, gánh nặng bệnh lý toàn cầu 
năm 2010, tần suất phình ĐMC ngực và bóc tách ĐMC ngực gia tăng từ 2,49/100,000 dân đến 2,78/100,000 dân từ năm 1990 đến năm 2010, tỉ lệ nam giới chiếm đa số. [2]

Tác giả Salvolini L. và cs nghiên cứu hình ảnh chụp CLĐT trên 132 BN được phẫu thuật cấp cứu do hội chứng ĐMC cấp cho thấy nhóm tuổi chủ yếu là 60-69 tuổi và 70-79 tuổi chiếm lần lượt là $30,3 \%$ và $27,3 \%$. Tác giả cũng ghi nhận có trường hợp $\mathrm{BN}$ ở nhóm tuổi $10-19$ tuổi và nhóm $20-29$ tuổi. Về giới tính , tác giả ghi nhận đa phần là nam giới chiếm tỉ lệ $67 \%$.

Tổn thương bóc tách ĐMC ngực là tổn thương thường gặp nhất trong hội chứng động mạch chủ cấp tính. Nghiên cứu chúng tôi nhóm bóc tách ĐMC ngực có phân bố tương đối đều và tăng dần theo nhóm tuổi, 17,4\% ở nhóm tuổi 51-60 tuổi và $26,1 \%$ ở nhóm tuổi $61-70$ tuổi. Các yếu tố nguy cơ của bóc tách ĐMC ngực chú yếu là các tình trạng làm tăng áp lực lên thành mạch máu.[6] Theo ghi nhận từ IRAD, 77\% TH bóc tách ĐMC ngực có tăng huyết áp hệ thống, trong đó bóc tách ĐMC ngực týp $B$ có tî̉ lệ tăng huyết áp cao hơn týp A (81\% so với 74\%) [8]. Ngoài ra, các báo cáo còn cho thấy nếu bóc tách ĐMC ngực xuất hiện ở những $\mathrm{BN}$ có tuổi < 40 tuổi thì có tới 68\%-95,7\% BN có hội chứng Marfan.

Năm 2015, tác giả Pape và cs báo cáo tổng hợp số liêu từ IRAD với 4428 BN cho thấy tuổi trung bình là $62 \pm 14,6$ tuổi ở nhóm bóc tách týp $A$ và $64 \pm 14,1$ tuổi ở nhóm bóc tách týp $B$. Tác giả ghi nhận chỉ khoảng $4 \%$ BN có hội chứng Marfan trong bóc tách ĐMC ngực. Về yếu tố nguy cơ, tăng huyết áp được ghi nhận nhiều nhất với tỉ lệ $77 \%$, tăng huyết áp ở nhóm bóc tách týp $\mathrm{B}$ nhiều hơn nhóm bóc tách týp $\mathrm{A}(81 \%$ so với $74 \%)$

Năm 2020, báo cáo tổng hợp của Gudbjartsson cho thây bóc tách ĐMC ngực týp $\mathrm{A}$ thường gặp ở nam giới chiếm $62-68 \%$. Tuổi trung bình của BN là tuổi già, trên 75 tuổi chiếm phần lớn. Tăng huyết áp là yếu tố nguy cơ thường gặp nhất của bóc tách ĐMC ngực týp $\mathrm{A}$ chiếm $67-86 \%$ theo các báo cáo[5]. Ngoài ra, hút thuốc lá và xơ vữa động mạch cũng được xem là các yếu tố nguy cơ độc lập của bóc tách ĐMC ngực týp A.

Tổn thương trên hình ảnh học. Vị trí và mức độ lan rộng của bóc tách ĐMC ngực rất quan trọng cho quyết định phẫu thuật của phẫu thuật viên. Chụp CLĐT là phương tiện hữu hiệu để chẩn đoán và đánh giá các tổn thương phối hợp trong bóc tách ĐMC ngực. Trên hình ảnh chụp CLĐT trong nghiên cứu, chúng tôi ghi nhận vi trí tổn thương chủ yếu ở ĐMC ngực đoạn lên chiếm $84,8 \%$, có $52,2 \%$ lan đến đoạn quai và 30,4\% TH lan đến ĐMC ngực đoạn xuống. 2/46 TH chỉ tổn thương đoạn xuống, 21/46 TH tổn thương từ đoạn lên đến quai đến đoạn xuống (hình 3.1). Ngoài ra, chúng tôi và ghi nhận có lố rách trên siêu âm tim là 32/46 (bảng 3.2). Trên siêu âm tim, hở van ĐMC nhẹ chiếm tỉ lệ chủ yếu $32,6 \%$, hở van $\mathrm{ĐMC}$ vừa và nặng chiếm tỉ lệ lần lượt là $17,4 \%$ và $23,9 \%$.

\section{KẾT LUÂ̂N}

Hình thái tổn thương trong hội chứng ĐMC cấp khá đa dạng và phức tạp, thường gặp nhất vẫn là hình thái bóc tách ĐMC kinh điển $(A D)$ chiếm tỷ lệ cao nhất $66,3 \%$; các hình thái ít gặp hơn là loét thủng PAU và huyết khối tụ thành IMH với tỷ lệ lần lượt là $8,9 \%$ và $23,8 \%$; nhóm có tỷ lệ ít gặp nhất là tổn thương $\mathrm{DMC}$ cấp tính sau thủ thuật (Iatrogenic) có tỷ lệ 2\% (2/101).

- Độ tuổi thường gặp nhất: bóc tách 26,1\% ở tuổi 61-70 tuổi; nhóm huyết khối thành và nhóm loét thủng, nhóm tuổi 61 -70 tuổi chiếm tỷ lệ cao nhất lần lượt là 45,8\% và 44,4\%

- Nhóm bóc tách kinh điển $(A D)$ : tổn thương chủ yếu ở ĐMC ngực đoạn lên chiếm $84,8 \%$, có $52,2 \%$ lan đến đoạn quai và $30,4 \%$ lan đến ĐMC ngực đoạn xuống

- Nhóm huyết khối thành (IMH): đoạn lên chiếm chủ yếu là $70 \%$, lan đến quai ĐMC chiếm $62,5 \%$ và ĐMC ngực đoạn xuống là 45,8\%.

- Nhóm phình ĐMC doa vỡ: tổn thương ĐMC ngực đoạn lên và đoạn xuống gần tương đương nhau chiếm tỉ lệ lần lượt là $55 \%$ và $50 \%$.

- Ở nhóm loét thủng (PAU): tổn thương đoạn quai ĐMC chiếm chủ yếu là $77,8 \%$.

- Nhóm tổn thương do thủ thuật/can thiệp (Iatrogenic): hiếm gặp, chỉ có 2 trường hợp

\section{TÀI LIỆU THAM KHẢO}

1. Anh Pham Tho Tuấn (2008), "Đă̆c điểm kỹ thuật phẩu thuật vùng quai động mạch chủ".Y học Thành phố Hồ Chí Minh, 13, pp. tr. 1-9.

2. Cường Lê văn (2012), "Các danng và kích thước động mạch của người Việt Nami", Nhà xuất bản $Y$ Hoc Thành phố Hồ Chí Minh, pp.

3. Hù̀ng Dương Đức (2018), "Kết quả sớm phẫu thuât Bentall tại bệnh viện Bạch Mai".Tạp chí Phẫu thuật lồng ngực - tim mạch Việt Nam, 20, pp. tr. $40-46$.

4. Hùng Phạm Mạnh (2015), "Mười điểm cần chú ý trong cảc khuyến cáo hiện nay về chẩn đoán phình và / hoăc bóc tách động mach chư".Tạp chí tim mạch học Việt Nam, 70, tr. 13 -14.

5. Lâm Triêu Phát Nguyễn Thái An, Trân Quyết Tiến, Phạm Thọ Tuấn Anh, Ngố Tuấn Anh, (2014), "Kết quả bước đầu đặt ống ghép nội mạch trong điều trị phình động mạch chủ ngực,". 
Tạp chí Y Dược Lâm Sàng 108, 9 (số 1), pp. 82-87.

6. Celikyay, Koner, Celikyay, et al. (2013). "Frequency and imaging findings of variations in human aortic arch anatomy based on multidetector computed tomography data". Clin Imaging, 37(6), pp. 1011-9.

7. Evangelista Arturo, Isselbacher Eric M.,
Bossone Eduardo, Gleason Thomas G., Eusanio Marco Di, et al. (2018), "Insights From the International Registry of Acute Aortic Dissection". Circulation, 137 (17), pp. 1846-1860.

8. Viscomi S.G. (2008), "Chapter 5: Computed tomography",in: J.S. Conselli, S.A.Lemaire, Aortic Arch Surgery, Blackwell, West Sussex-UK, pp. 39-57.

\title{
NGHIÊN CỨU BÀO CHẾ VIÊN NANG TỪ BÀI THUỐC LƯC VI HOÀN
}

\author{
Nguyễn Đăng Thoại ${ }^{1}$, Nguyễn Mạnh Huy ${ }^{1}$, Khưu Mỹ Lệ
}

TÓM TẮT

Mục tiêu: Bào chế Luc vị hoàn ở dang thuốc viên nang để chuẩn hóa liều dùng và thuẩn tiện khi sử dụng. Đối tượng và phương pháp: Chế biến nguyên liệu bằng phương pháp nấu cao hoă̆c xay bột. Công thức viên nang cứng được xây dựng và chọn lựa dưa vào đô ẩm, tỷ trọng biểu kiến và độ trơn chảy của khối bột đóng nang và các thiết bị tương ứng. Kết quả: Đã bào chếđược viên nang lục vị với liều dùng quy đổi là 3 viên/lần, ngày uống 2 lần. Kết quả định tính cho thấy viên nang lục vị hoàn có phản ứng dương tính với các thuốc thử ứng với thành phần dược liệu và trên sắc ký đồ có các vết cùng giá trị $R_{f}$ và cùng màu sắc với các vết trên sắc ký đồ của dung dịch đối chiếu. Viên đạt yêu cầu về độ đồng đều khối lượng, độ rã theo quy định của viên nang. Kết luận: Viển nang chứa cao luc vi hoàn đã được bào chế đat yêu cầu về chất lượng của viên nang, có tác dụng bồi bổ khí huyết, dùng điêu trị hỗ trơ cho người đau lưng, nhức mỏi đâu gối, hoa mắt, chóng mặt, sử dụng thuân tiên.

Từ khóa: Lục vị hoàn, bồi bổ khí huyết, đau lưng, nhức mỏi đầu gối,hoa mắt.

\section{SUMMARY}

\section{PREPARATION OF CAPSULE CONTAINING} EXTRACT FROM SIX TYPES OF MEDICINAL HERBS

Objectives: To prepare Luc vi hoan in capsule form to standardize dosage and convenient to use. Materials and methods:The herb was extracted by hot water orground into powder. Moisture, density and smoothness of the powder were analized to select hard capsule formulations. Results: Luc vi capsules were prepared with an equivalent dose of 3 capsules/time, twice a day. Starch was added to form one capsule. As a result, capsules had a positive reaction to the reagents. On the chromatogram, there were traces of the same $R_{\mathrm{f} v a l u e}$ and the same color as those on the chromatogram of reference medicinal herbs. Luc vi hoan capsules meet the requirements of mass uniformity and disintegration prescribed in Vietnamese pharmacopoeia. Conclusions: Luc vi

${ }^{11}$ Trường $Đ H$ Y khoa Phạm Ngoc Thạch

Chịu trách nhiệm chính: Nguyển Đăng Thoại

Email: thoaind@pnt.edu.vn

Ngày nhận bài: 2/1/2021

Ngày phản biên khoa hoc: 7/2/2021

Ngày duyệt bài: 3/3/2021 hoan capsuleswere prepared and the quality was investigated. It has the effect of nourishing blood, supporting treatment for people with back pain, knee pain, dizziness. Besides, capsule form is convenient for patients.

Keywords: Luc vi hoan, nourishing blood, back pain, knee pain, dizziness.

\section{I. ĐẶT VẤN ĐỀ}

Lục vị hoàn là bài thuốc nổi tiếng của y học cổ truyền Việt Nam, có trong bộ sách Hải Thượng y tông tâm lĩnh của Hải Thượng Lãn Ông Lê Hữu Trác. Trải qua hàng trăm năm, Lục vị hoàn được xem là một trong những bài thuốc căn bản của Đông y có giá trị cao trong chữa bệnh. Ngày nay, Lục vị hoàn có tên trong Danh mục thuốc thiết yếu của Bộ $Y$ tế ban hành vào năm 2018. Bài thuốc Lục vị hoàn gôm các vị thuốc: Thục địa, sơn thù, sơn dược, mẫu đơn, trạch tả, phục linh được bào chế dưới dạng viên hoàn cứng, đóng chai. Để góp phần chuẩn hóa liều dùng và tạo sự tiện dụng cho người bệnh trong đời sống hiện đại ngày nay, chúng tôi nghiên cứu hiện đại hóa bài thuốc Lục vị hoàn ở dạng viên nang cứng với số viên tối thiểu của liều sử dụng.

\section{II. ĐỐl TƯỢNG VÀ PHƯƠNG PHÁP NGHIÊN CỨU \\ 2.1. Đối tượng nghiên cứu}

2.1.1. Nguyên liệu. Các dược liệu được sấy khô ở $50^{\circ} \mathrm{C}$. Tất cả các dược liệu đều đạt tiêu chuẩn Dược điển Việt Nam V.

- Thục địa(Rehmania glutinosa Libosch). Bộ phận dùng: Rễ (Radix Rehmanniae glutinosae praeparata)

- Sơn thù (Cornus officinalis Sieb. et Zucc). Bộ phận dùng: Quả (Fructus Corni officinalis)

- Hoài sớn (củ mài, sớn dược) (Dioscorea persimilis Prain et Burk). Bộ phận dùng: Rễ củ (Tuber Dioscoreae persimilis)

- Mẫu đơn bì (Paeonia suffruticosa Andr). Bô phận dùng: Vỏ rễ (Cortex Paeoniae suffruticosae)

Trạch tả (Alisma plantago-aqulica L. var. orientale Samuels). Bộ phận dùng: Rễ củ (Rhizoma Alismatis) 